\title{
Easy One-Pot Synthesis of Energy Transfer Cassettes
}

\author{
W.G. Skene* and Stéphane Dufresne \\ Department of Chemistry, University of Montreal \\ C.P. 6128 , succ. Centre-ville, Montreal \\ QC, H3C 3J7 \\ Canada
}

Supporting Information 


\section{Table of Contents}

Synthetic procedures: Pages $3-6$

Absorption spectra of energy transfer cassettes: Pages 7 - 10

Fluorescence spectra of energy transfer cassettes: Pages $11-14$ 
Instrumentation. ${ }^{1} \mathrm{H}$ NMR spectra of the polymers were obtained on a Bruker 300 spectrometer using $5 \mathrm{~mm}$ o.d. tubes in [D]chloroform. Absorption measurements were done on a Cary-500i UV-Visible spectrometer by Varian while emission studies were done a Varian Cary Eclipse fluorimeter after degassing the sample thoroughly with argon for 20 minutes in anhydrous acetonitrile. Anthracene was recrystalized twice from absolute ethanol and used as an actinometer.

\section{SYNTHESIS Of ENERGY TRANSFER CASSETTES:}

\section{5-[(6,7-Dihydro-naphthalen-2-ylimino)-methyl]-thiophene-2-carbaldehyde}

(2): In a round bottom flask $(250 \mathrm{ml})$ was added 2,5-thiophenedicarboxaldehyde (1, $145 \mathrm{mg}, 1.04 \mathrm{mmol}$ ) in $200 \mathrm{~mL}$ of chloroform to which was added 1aminonaphthalene $(148 \mathrm{mg}, 1.04 \mathrm{mmol})$. The mixture was refluxed for 3 to 4 hours with slow evaporation of the solvent. Complete removal of the solvent leads to an orange solid which was purified by flash chromatography $\left(\mathrm{SiO}_{2}\right)$ using $100 \%$ hexane. The product was isolated as a bright yellow solid (69\%). M.p. : $125^{\circ}-127^{\circ} \mathrm{C} .{ }^{1} \mathrm{H}$ NMR: $(300 \mathrm{MHz}$, [D] chloroform): $\delta=9.99(\mathrm{~s}, 1 \mathrm{H}), 8.68(\mathrm{~s}$, $1 \mathrm{H}), 8.37(\mathrm{~m}, 1 \mathrm{H}), 7.86(\mathrm{~m}, 1 \mathrm{H}), 7.78(\mathrm{~m}, 2 \mathrm{H}), 7.55(\mathrm{~m}, 3 \mathrm{H}), 7.46(\mathrm{t}, 1 \mathrm{H}), 7.12$ (dd, $1 \mathrm{H}) .{ }^{13} \mathrm{C}$ NMR $(60 \mathrm{MHz},[\mathrm{D}]$ chloroform): $\delta=183.80,152.19,136.41$, 131.87, 128.06, 127.57, 127.11, 126.59, 126.26, 124.32, 113.08. El-MS: m/z $264.99\left([\mathrm{M}]^{+}, 100 \%\right)$.

5-(Anthracen-2-yliminomethyl)-thiophene-2-carbaldehyde (3): In a $250 \mathrm{ml}$ round bottom flask was dissolved 1 (145 mg, $1.04 \mathrm{mmol}$ ) in $150 \mathrm{~mL}$ of chloroform. To this was added with vigorous stirring, 9-aminoanthracene (200 $\mathrm{mg}, 1.04 \mathrm{mmol}$ ) along with a catalytic amount of acetic acid followed by refluxing for four days. The title compound was isolated as a light brown powder (44\%) by flash chromatography $\left(\mathrm{SiO}_{2}\right)$. M.p.: $280^{\circ} \mathrm{C} .{ }^{1} \mathrm{H} \mathrm{NMR}(300 \mathrm{MHz},[\mathrm{D}]$ chloroform): $\delta=10.00(\mathrm{~s}, 1 \mathrm{H}), 8.83(\mathrm{~s}, 1 \mathrm{H}), 8.44(\mathrm{~d}, 2 \mathrm{H}), 8.03(\mathrm{~m}, 3 \mathrm{H}), 7.86(\mathrm{~s}$, $1 \mathrm{H}), 7.81(\mathrm{~d}, 1 \mathrm{H}), 7.62(\mathrm{~d}, 1 \mathrm{H}), 7.50(\mathrm{~m}, 3 \mathrm{H})$. 


\section{\{5-[(6,7-Dihydro-naphthalen-2-ylimino)-methyl]-thiophen-2-ylmethylene\}-}

naphthalen-2-yl-amine (4): In a $100 \mathrm{ml}$ round bottom flask was added 1 (145 $\mathrm{mg}, 1.04 \mathrm{mmol}$ ) and dissolved in $20 \mathrm{~mL}$ of chloroform to which was subsequently added 1-aminonaphthalene (296 mg, $2.07 \mathrm{mmol}$ ) and a catalytic amount of acetic acid. The resulting yellow solution was refluxed for three hours and the solvent removed. Purification by flash chromatography $\left(\mathrm{SiO}_{2}\right) 100 \%$ hexane yielded the titled product as a dark yellow/brown solid (52\%). M.p.: $168^{\circ}-170^{\circ} \mathrm{C} .{ }^{1} \mathrm{H}$ NMR (300 MHz, [D] chloroform): $\delta=8.72(\mathrm{~s}, 1 \mathrm{H}), 8.46(\mathrm{~m}, 1 \mathrm{H}), 7.86(\mathrm{~m}, 1 \mathrm{H}), 7.76(\mathrm{~d}$, $1 \mathrm{H}), 7.53(\mathrm{~m}, 4 \mathrm{H}), 7.15$ (dd, $1 \mathrm{H}) .{ }^{13} \mathrm{C} N M R(60 \mathrm{MHz}$, [D] chloroform): $\delta=152.77$, $148.28,147.27,134.38,132.53,129.51,127.98,126.99,126.40,126.32$, 124.53(2C), 113.04. El-MS: m/z 391.1([M] $\left.]^{+}, 15 \%\right)$.

\section{Anthracen-2-yl-[5-(naphthalen-2-yliminomethyl)-thiophen-2-ylmethylene]-}

amine (5): Using the conditions as for 2 , the reaction progress was monitored by TLC. Once judged completed, 1.1 equivalents of 9-aminoanthracene was added to the mixture and then continued to reflux. The reaction was worked up using similar methods as described. ${ }^{1} \mathrm{H}$ NMR $(300 \mathrm{MHz}$, [D] chloroform): $\delta=8.83$ (s, $1 \mathrm{H}), 8.68(\mathrm{~s}, 1 \mathrm{H}), 8.44(\mathrm{~d}, 2 \mathrm{H}), 8.37(\mathrm{~m}, 2 \mathrm{H}), 8.03(\mathrm{~m}, 3 \mathrm{H}), 7.86(\mathrm{~m}, 1 \mathrm{H}), 7.78(\mathrm{~m}$, $2 \mathrm{H}), 7.55(\mathrm{~m}, 6 \mathrm{H}), 7.46(\mathrm{t}, 1 \mathrm{H}), 7.11(\mathrm{~s}, 2 \mathrm{H})$. El-MS: m/z 440.1([M] $\left.]^{+}, 10 \%\right)$.

(6,7-Dihydro-naphthalen-2-yl)-thiophen-2-ylmethylene-amine (6): In a $100 \mathrm{ml}$ round bottom flask was added 1 (75 mg, $0.53 \mathrm{mmol}$ ) and dissolved in $50 \mathrm{~mL}$ chloroform to which was added 1-aminonaphthalene $(151 \mathrm{mg}, 1.07 \mathrm{mmol})$ in addition to a catalytic amount of acetic acid. The resulting solution was refluxed for two hours then purified by flash chromatography $\left(\mathrm{SiO}_{2}\right)$ to yield the title product as a dark brown solid (96\%). ${ }^{1} \mathrm{H}$ NMR $(300 \mathrm{MHz}$, [D] chloroform): $\delta=$ $8.70(\mathrm{~s}, 1 \mathrm{H}), 8.42(\mathrm{~m}, 1 \mathrm{H}), 7.88(\mathrm{~m}, 1 \mathrm{H}), 7.78(\mathrm{~d}, 1 \mathrm{H}), 7.57(\mathrm{~m}, 4 \mathrm{H}), 7.47(\mathrm{t}, 1 \mathrm{H})$, $7.20(\mathrm{q}, 1 \mathrm{H}), 7.14(\mathrm{~d}, 1 \mathrm{H}) .{ }^{13} \mathrm{C}$ NMR $(60 \mathrm{MHz},[\mathrm{D}]$ chloroform): $\delta=153.48$, 149.04, 143.61, 134.36, 132.64, 131.01, 129.32, 128.24, 128.02, 126.88, 126.41, 126.37, 126.22, 124.49, 113.27. 
carboxaldehyde $(75 \mathrm{mg}, 0.66 \mathrm{mmol}$ ) was mixed with 1-aminonaphthalene (96 $\mathrm{mg}, 0.66 \mathrm{mmol}$ ) in chloroform and refluxed for 3 hours. The solvent was removed and the product isolated as a yellow solid after purification by flash chromatography (150 mg, $96 \%){ }^{1} \mathrm{H}$ NMR $(300 \mathrm{MHz}$, [D] chloroform): $\delta=8.7$ (s, $1 \mathrm{H}), 8.42(\mathrm{~m}, 1 \mathrm{H}), 7.88(\mathrm{~m}, 1 \mathrm{H}), 7.57(\mathrm{~m}, 5 \mathrm{H}), 7.47(\mathrm{t}, 1 \mathrm{H}), 7.24(\mathrm{~d}, 1 \mathrm{H}) .{ }^{13} \mathrm{C}$ NMR (60 MHz, [D] chloroform): $\delta=153.5,149.0,143.6,134.4,132.6,131.0$, 129.3, 128.2, 128.0, 126.9, 126.4, 126.2, 124.5, 113.3. FAB-MS $\left(\mathrm{N}_{2}\right): \mathrm{m} / \mathrm{z} 237.1$ $\left([\mathrm{M}]^{+}, 100 \%\right)$. HRMS calc'd for $\mathrm{C}_{15} \mathrm{H}_{11} \mathrm{NS} 237.06122$ found 237.061221 .

\section{Anthracen-9-yl-thiophen-2-ylmethylene-amine (8): 2-Thiophene} carboxaldehyde (75 $\mathrm{mg}, 0.66 \mathrm{mmol}$ ) was mixed with 9-aminoanthrancene (127 $\mathrm{mg}, 0.66 \mathrm{mmol}$ ) in chloroform and refluxed for 3 hours. The solvent was removed and the product isolated as a yellow solid after purification by flash chromatography (140 mg, $74 \%)^{1} \mathrm{H}$ NMR $(300 \mathrm{MHz}$, [D] chloroform): $\delta=9.0$ (s, $1 \mathrm{H}), 8.57(\mathrm{~d}, 2 \mathrm{H}), 8.11(\mathrm{~d}, 1 \mathrm{H}), 8.05(\mathrm{~m}, 2 \mathrm{H}), 7.86(\mathrm{~m} \mathrm{1H}), 7.83(\mathrm{~d}, 1 \mathrm{H}), 7.73(\mathrm{~d}$, 1H) $7.58(\mathrm{dd}, 1 \mathrm{H}), 7.48(\mathrm{~m}, 2 \mathrm{H}), 7.25(\mathrm{t}, 1 \mathrm{H})$. FAB-MS $\left(\mathrm{N}_{2}\right): \mathrm{m} / \mathrm{z} 287.1\left([\mathrm{M}]^{+}\right.$, $100 \%$ ). HRMS calc'd for $\mathrm{C}_{19} \mathrm{H}_{13} \mathrm{NS} 287.07637$ found 287.007687 .

Anthracen-9-ylmethylene-naphthalen-2-yl-amine (9): 1-Aminonaphthalene (69 $\mathrm{mg}, 0.49 \mathrm{mmol}$ ) and 9-anthraldehyde (100 $\mathrm{mg}, 0.45 \mathrm{mmol}$ ) were refluxed in chloroform for 8 hours and the title compound isolated as a red solid after flash chromatography (120 mg, 75\%). M.p. > 225 $\mathrm{C} .{ }^{1} \mathrm{H}$ NMR $(300 \mathrm{MHz},[\mathrm{D}]$ chloroform): $\delta=11.55(\mathrm{~d}, 2 \mathrm{H}), 8.99(\mathrm{~m}, 3 \mathrm{H}), 8.74(\mathrm{~s}, 2 \mathrm{H}), 8.07(\mathrm{~m} \mathrm{3H}), 7.72(\mathrm{~m}$, $3 \mathrm{H}), 7.54(\mathrm{~m}, 3 \mathrm{H})$. FAB-MS $\left(\mathrm{N}_{2}\right): \mathrm{m} / \mathrm{z} 331.4\left([\mathrm{M}]^{+}, 100 \%\right) .{ }^{13} \mathrm{C} \mathrm{NMR}(60 \mathrm{MHz},[\mathrm{D}]$ chloroform): $\delta=154.7,148.5,143.5,134.7,132.6,132.5,132.2,131.9,130.8$, 130.2, 129.2, 129.0, 128.6, 126.9, 126.8, 126.7, 126.3, 122.3, 119.1.

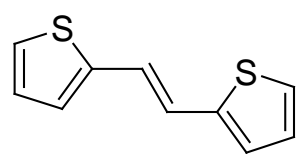


Structure used as reference for $\mathrm{C}=\mathrm{C}$ bond distances, trans-1,2-di-2thenylethylene, from Zobel et al. ${ }^{1}$ 


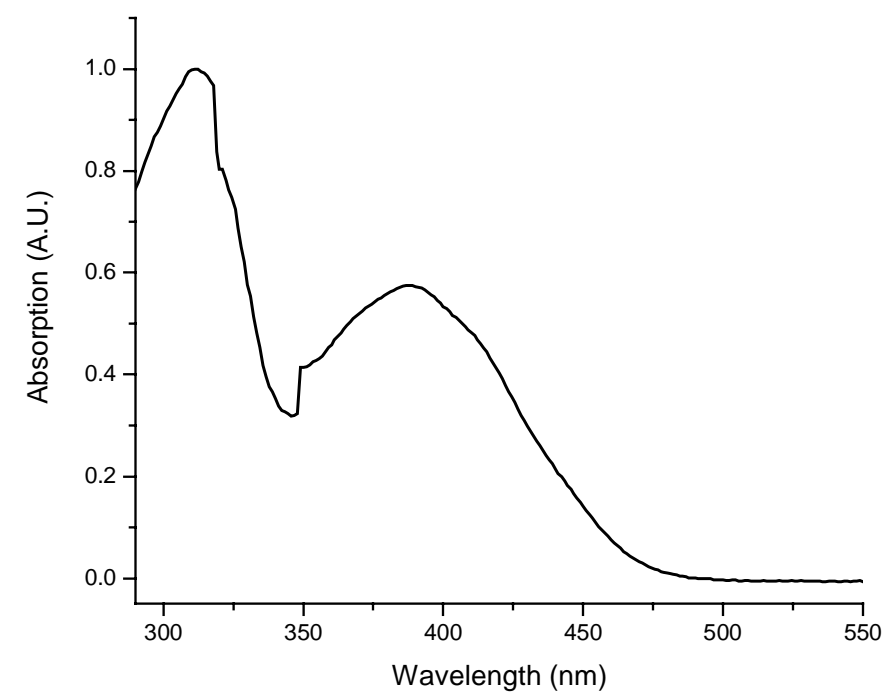

Absorption spectrum of $\mathbf{2}$ in acetonitrile.

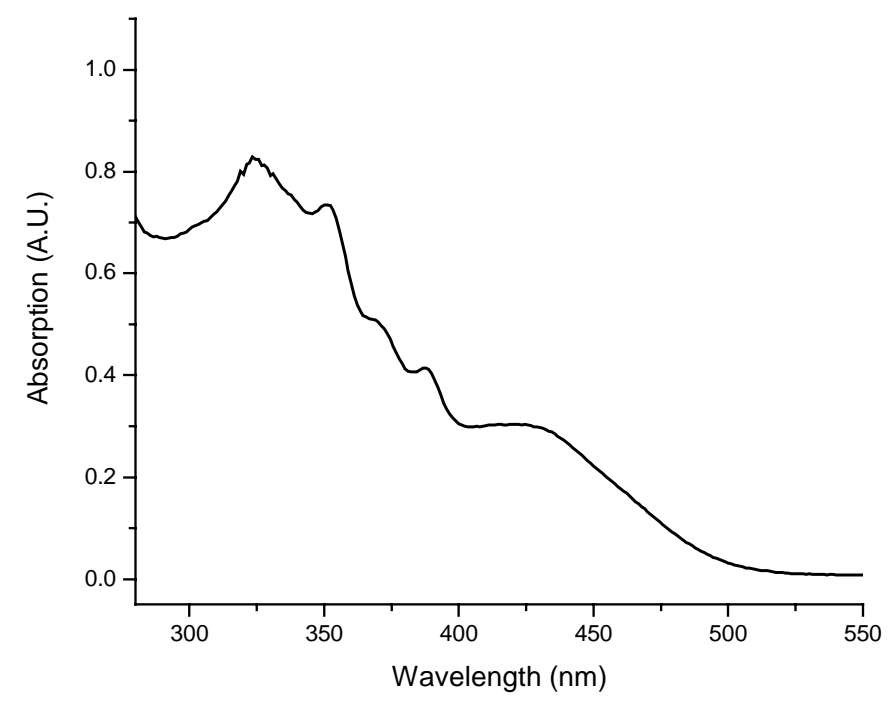

Absorption spectrum of $\mathbf{3}$ in acetonitrile. 


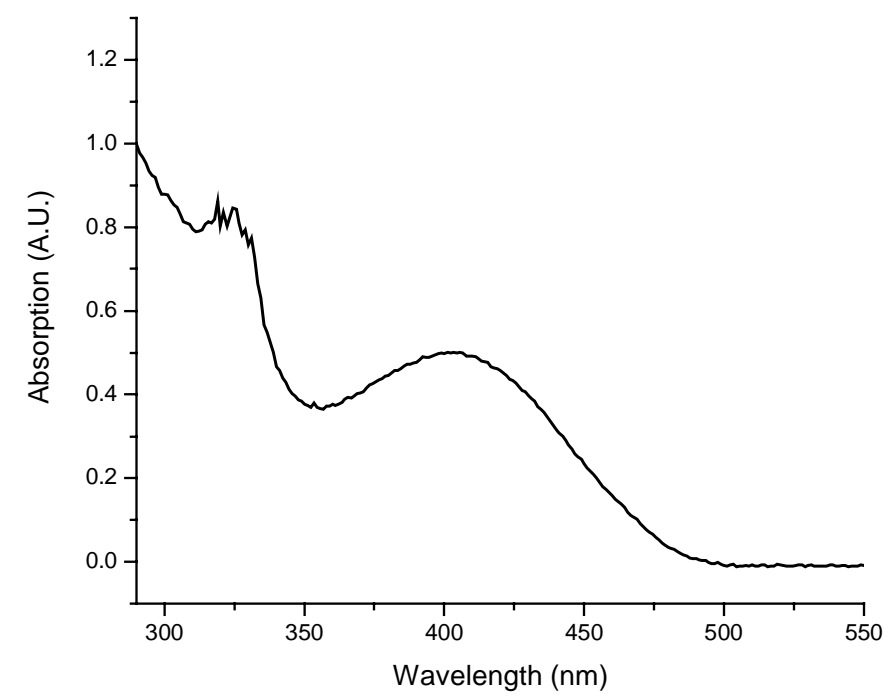

Absorption spectrum of $\mathbf{4}$ in acetonitrile.

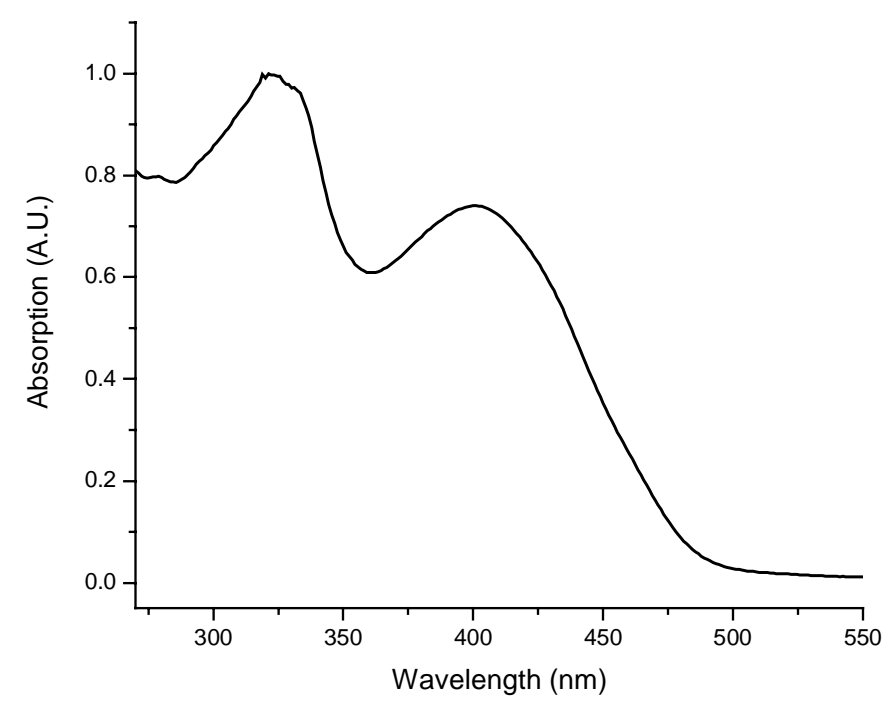

Absorption spectrum of $\mathbf{5}$ in acetonitrile. 


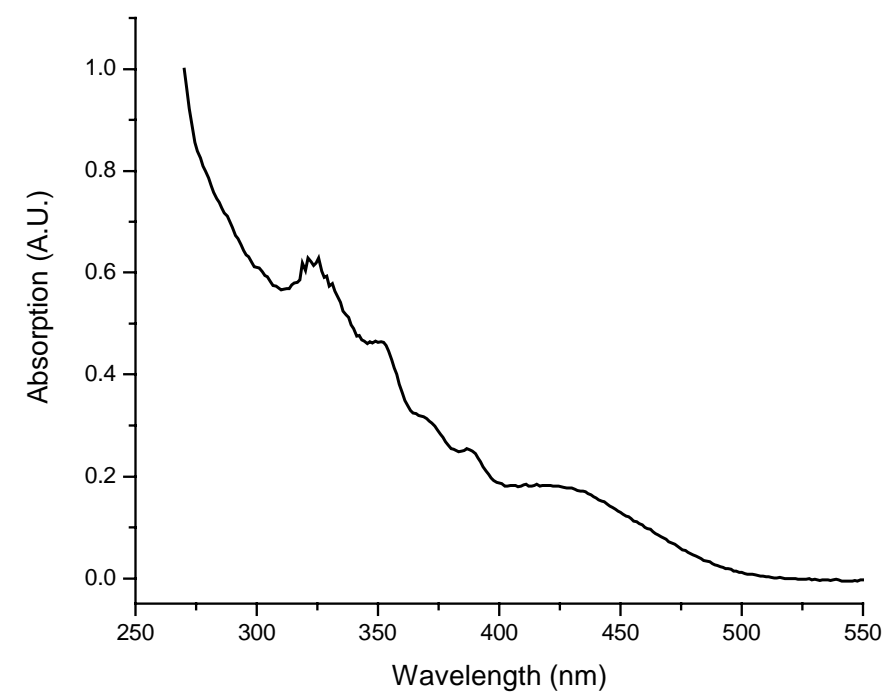

Absorption spectrum of 6 in acetonitrile.

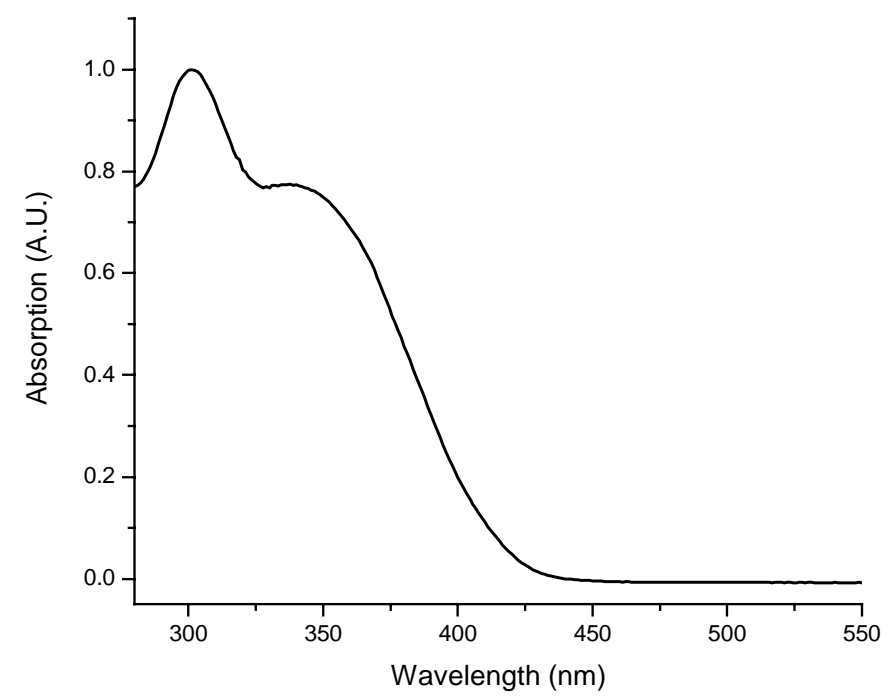

Absorption spectrum of $\mathbf{7}$ in acetonitrile. 


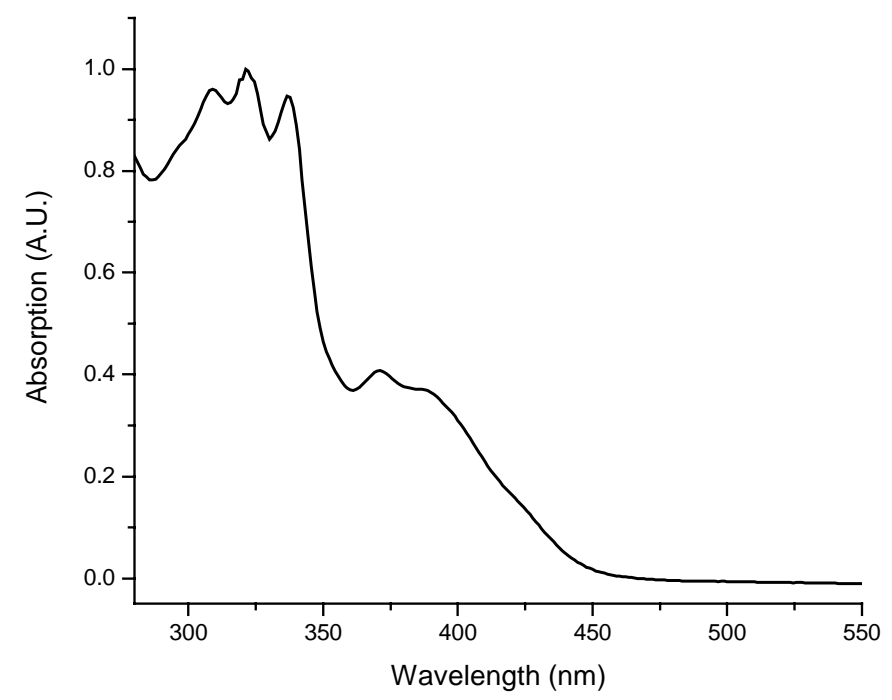

Absorption spectrum of $\mathbf{8}$ in acetonitrile.

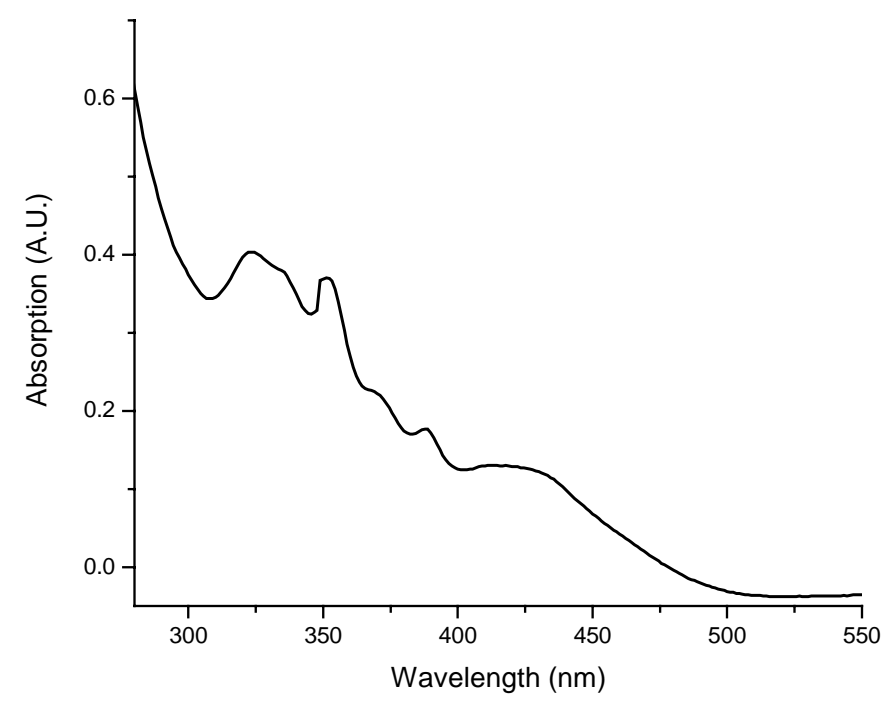

Absorption spectrum of $\mathbf{9}$ in acetonitrile. 


\section{FLUORESCENCE STUDIES:}

The fluorescence spectra are uncorrected and were recorded without filters subsequently leading to the scatter peaks from the frequency doubling of the excitation wavelengths. All spectra were recorded at room temperature and the samples were prepared with matching absorbances at the given excitation wavelengths, below 0.2. Removal of oxygen from the acetonitrile solutions was obtained by bubbling with argon in order to eliminate unwanted quenching of the excited states by oxygen. The quantum yields of energy transfer were determined by calculating the areas under the curves relative to the known quantum yield of fluorescence of anthracene.

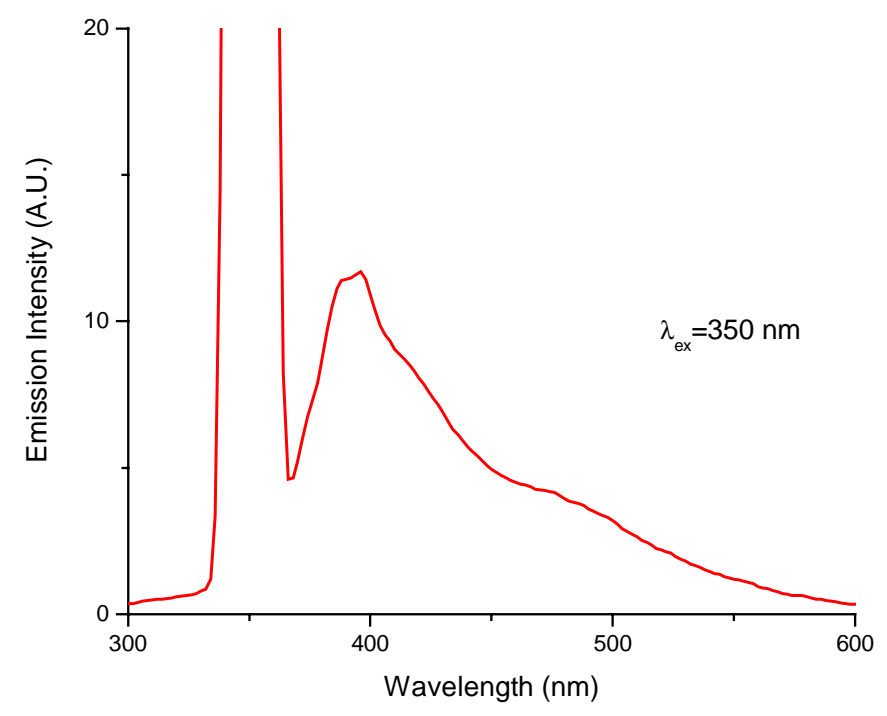

Emission spectrum of $\mathbf{2}$ in acetonitrile. 


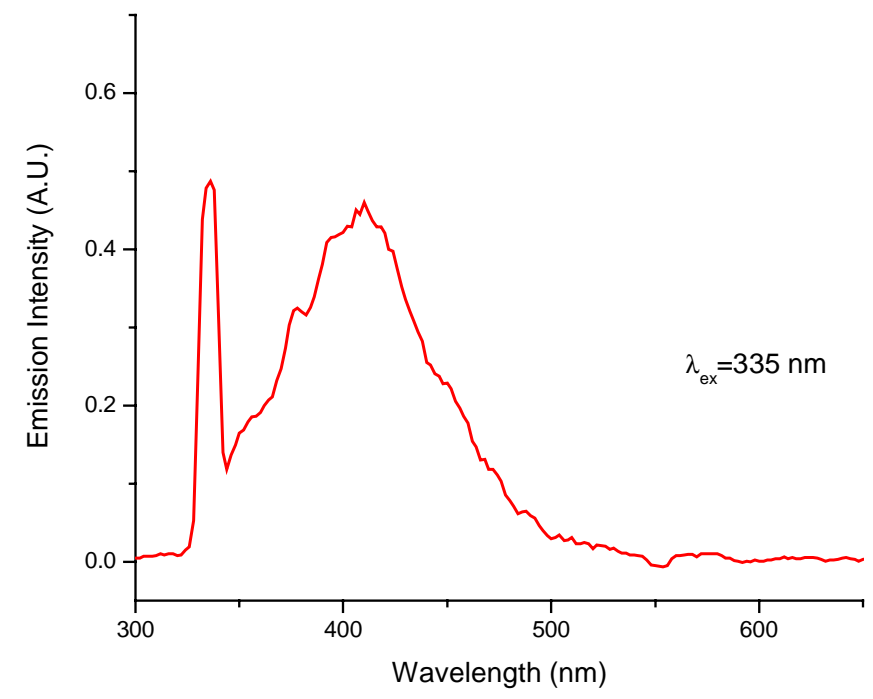

Emission spectrum of $\mathbf{4}$ in acetonitrile.

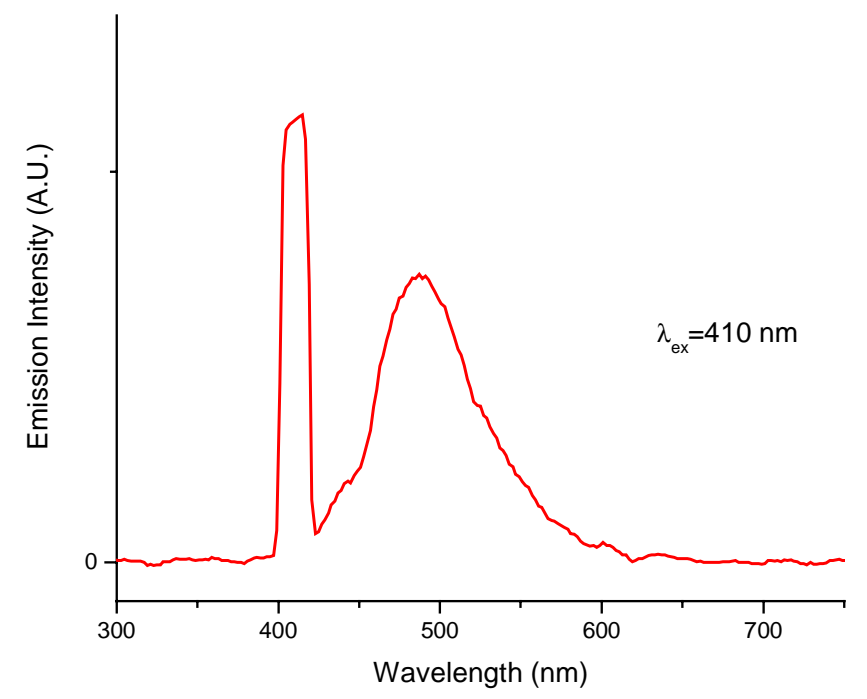

Emission spectrum of $\mathbf{3}$ in acetonitrile. 


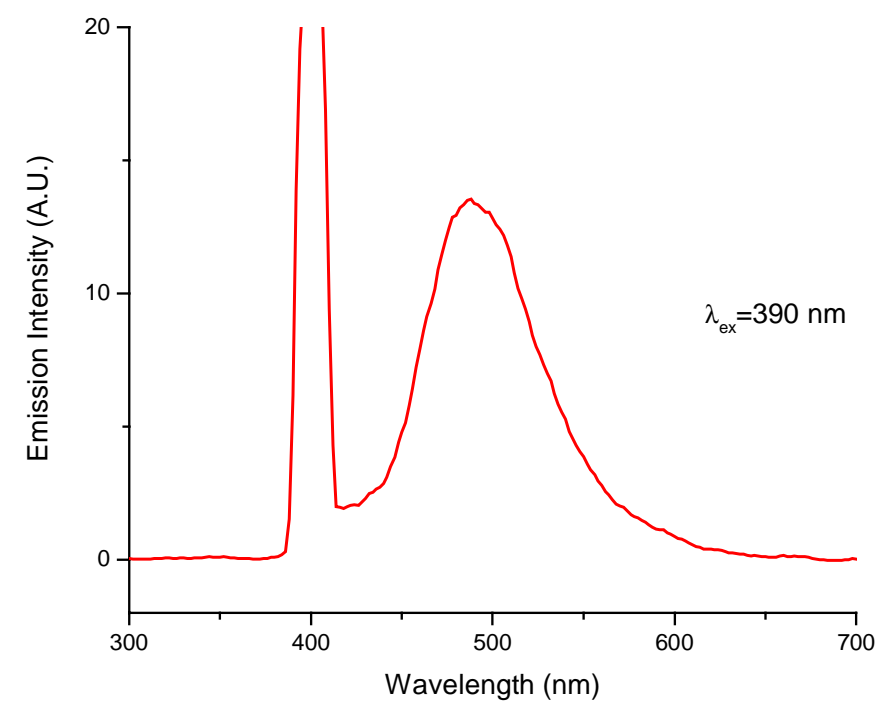

Emission spectrum of 6 in acetonitrile.

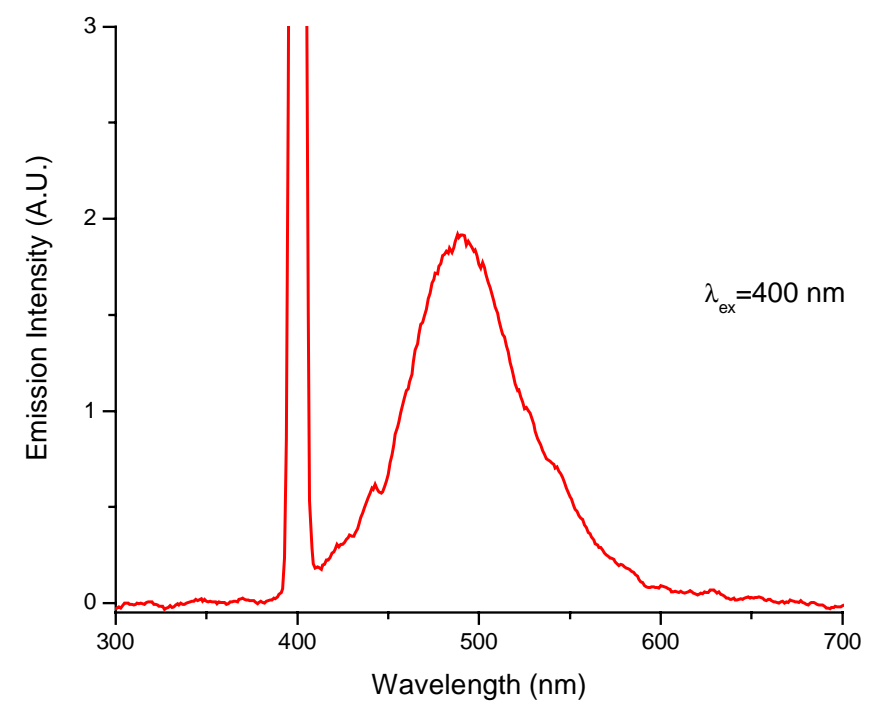

Emission spectrum of $\mathbf{5}$ in acetonitrile. 


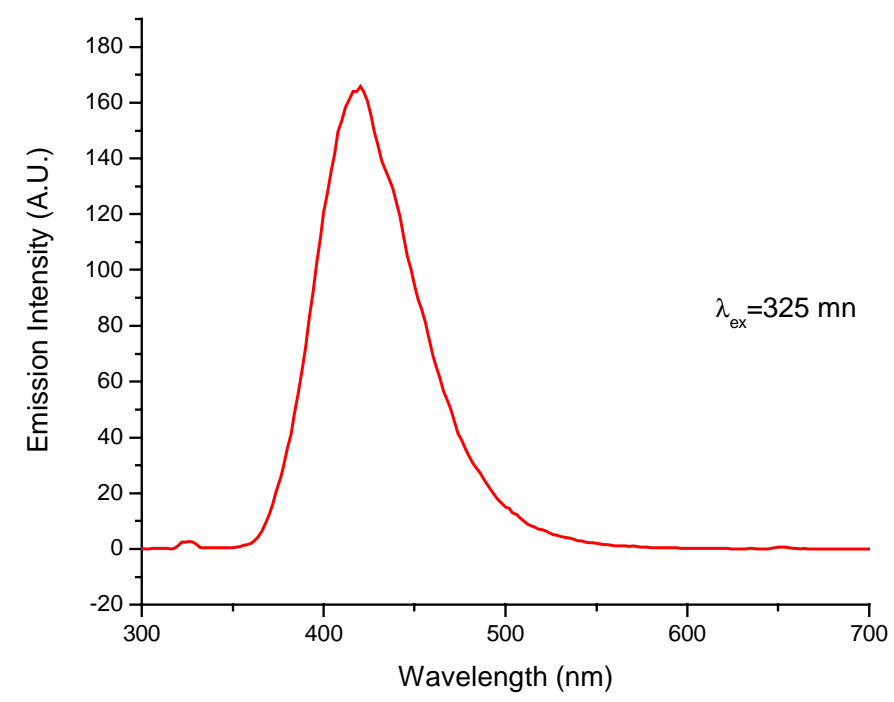

Emission spectrum of $\mathbf{7}$ in acetonitrile.

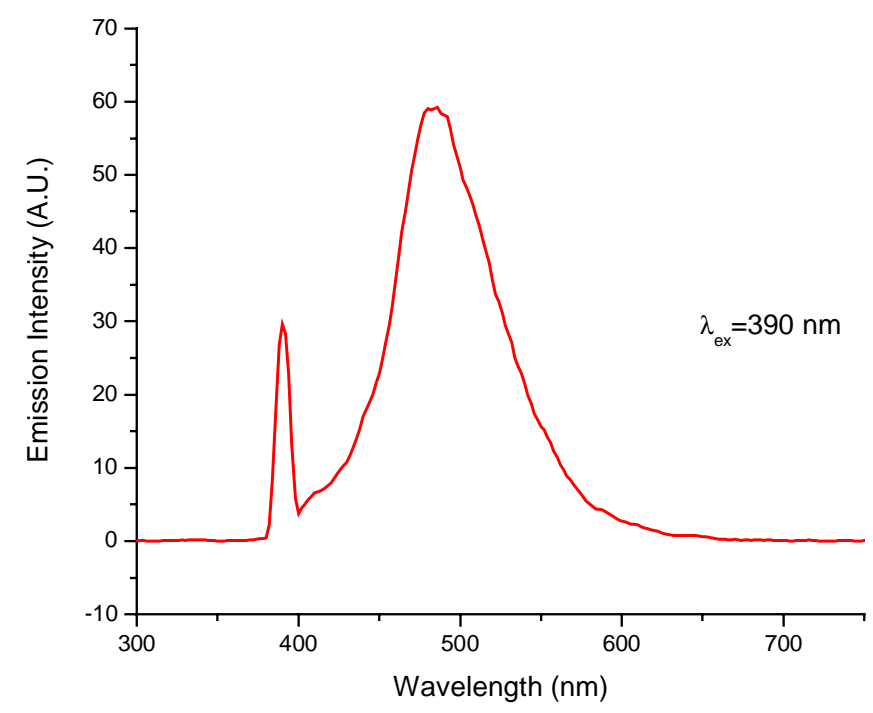

Emission spectrum of $\mathbf{8}$ in acetonitrile. 


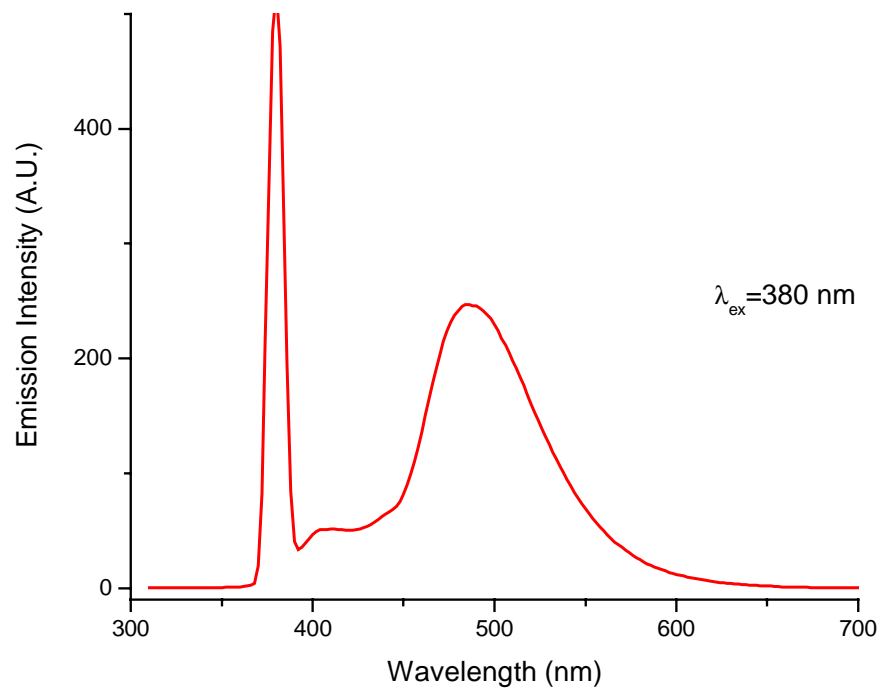

Emission spectrum of $\mathbf{9}$ in acetonitrile. 